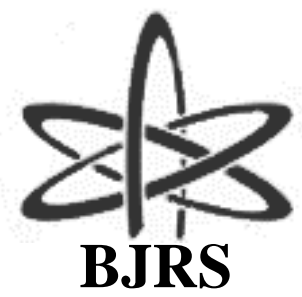

BRAZILIAN JOURNAL

$\mathrm{OF}$

RADIATION SCIENCES

09-02B (2021) 01-19

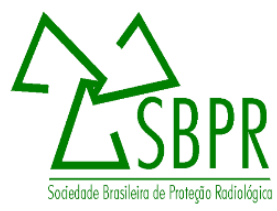

\title{
Overview of seismic probabilistic safety assessment applied to a nuclear installation located in a low seismicity zone
}

\author{
Ellison Amaro de Oliveira ${ }^{a}$, Patricia da Silva Pagetti de Oliveira ${ }^{a}$, Miguel Mattar \\ Neto $^{\mathrm{a}}$, Marcos Coelho Maturana ${ }^{\mathrm{b}}$ \\ ${ }^{a}$ Instituto de Pesquisas Energéticas e Nucleares (IPEN - CNEN/SP) / 05508-000, São Paulo, SP, Brazil \\ ellison.oliveira@ipen.br \\ patricia@ipen.br \\ mmattar@ipen.br
}

${ }^{b}$ Laboratório de Análise, Avaliação e Gerenciamento de Risco, LabRisco - USP, 05508-030 São Paulo - SP, Brazil

marcos@labrisco.usp.br

\begin{abstract}
Deterministic and probabilistic safety analysis methodologies have been developed and updated based on operational experience, investigation of past incidents or accidents, and analysis of postulated initiating events in nuclear plants in order to maintain the protection of workers, the public and the environment. The evaluation of accident sequences and the total radiological risk resulting from off-site releases are general objectives addressed by these methodologies. There are hazards that continually challenge the safety of a nuclear facility or its nearby area. In particular, seismic events represent a major contributor to the risk of a nuclear accident. Different levels of ground motion induced by earthquakes may be experienced by structures, systems and components (SSCs) of an installation. In this context, a seismic hazard analysis, seismic demand analysis and seismic fragility analysis must be carried out in order to characterize the local seismic hazard and seismic demands on SSCs, allowing an adequate seismic classification of SSCs, even for installations located in sites with low seismicity. In this article, a general description of the Seismic Probabilistic Safety Assessment (Seismic PSA) methodology is presented, emphasizing the supporting studies. This methodology shall be applied to an experimental nuclear installation containing a PWR reactor designed for naval propulsion to be installed in a low seismicity zone in Brazil.
\end{abstract}

Keywords: Seismic Probabilistic Safety Assessment methodology, support studies, low seismicity zone. 


\section{INTRODUCTION}

The design of a nuclear installation is feasible when the radiological risk associated with its operation is as low as reasonably achievable. Radiological levels are evaluated according to the design basis and are supposed to be maintained at an acceptable value over plant lifetime [1]. The evaluation of the installation radiological risk with regard to public health, economy and environment, considering abnormal or accident conditions, may be done using two complementary approaches, the Deterministic Safety Analysis (DSA) and the Probabilistic Safety Assessment (PSA) [2]. In general, the DSA is the primary approach to the safety assessment of nuclear installations and regulatory authorities require that operating organizations or license applicants demonstrate safety margins during normal operations and transient conditions expected to occur during plant lifetime. In addition, items designed to prevent design basis accidents and to minimize their consequences should have their adequacy demonstrated. The PSA consists of a comprehensive and integrated assessment of nuclear plant safety that derives numerical estimates for the risk of accidents that cause significant damage to the radioactive sources in the plant. In this point, an initial plant state is considered and the probability, progression, and consequences of multiple failures (equipment failures, human errors and internal/external hazards) are assessed. A PSA can be considered a complementary tool for the regulatory decision-making process, in which a designer or operator may use it in several applications, in all lifetime phases of the plant (design, construction, commissioning, operation and decommissioning). Besides, to assess the risk associated with accidents involving damage to radioactive sources at the plant, it is essential that all groups of internal events and internal/external hazards be considered for the safety analysis.

Internal events originating from sources located inside the reactor building or on the plant site are related to random failures of Structures, Systems and Components (SSCs) and human errors in procedures. Internal hazards such as fire and floods must also be included in the scope of a safety analysis. External hazards originating outside the plant site may be natural or man-induced, or a combination thereof.

With the evolution of nuclear plant design regarding passive safety systems, operational experience of existing plants and new technologies, the risks associated with internal events have 
decreased. Nevertheless, the assessment of impacts regarding internal fire, internal floods, seismic events and other external hazards has gained more attention.

External hazards analyses are largely site and plant specific. These events may specially affect building structures (including containment and/or confinement), ventilation and air-conditioning systems, cooling systems and their ultimate heat sink, electrical power supply, safety systems components and plant accessibility.

Among the fundamental roles of a PSA, the identification of the SSCs capacity to support the occurrence of an external event is one of the most important results. However, it is still a challenge to estimate risk metrics, such as Core Damage Frequency (CDF) and/or Large Early Release Frequency (LERF), for external hazards with low probability of occurrence and high impact. This is the case of seismic events, as they continually challenge nuclear plant safety and large levels of earthquake-induced ground motions can potentially be experienced in the site of a nuclear plant and in its vicinity.

Furthermore, earthquake-induced initiating events represent hazards with complex characteristics. Ground motion levels range forms a continuous scale and SSCs failure probabilities depend on particular ground motions. In addition, the following specificities may be mentioned [3]:

- Seismic events can damage not only active components, but also structures which under normal conditions have extremely low failure probabilities, generating specific failure modes that are not reflected in the accident sequence models for other initiating events;

- Seismic events can have a large spatial impact, damaging multiple structures, redundant systems and multi-unit sites;

- Mitigating the effect of a seismic event may require more complex actions than the ones taken to mitigate other initiating events;

- Seismic PSA comprise larger uncertainties, which propagate from hazard and fragility analyses;

- Depending on the seismic event magnitude, ground motions may exceed plant design basis criteria. Therefore, in a Seismic PSA, SSCs failure probabilities shall be evaluated considering beyond design basis ground motions. 
Some supporting analyses are critical with respect to the development of a Seismic PSA. The main results generated from the supporting analyses required to quantify the plant seismic risk are: probabilities of earthquakes of different intensities (seismic hazard), plant structural response (seismic demand) and SSCs susceptibility to earthquake intensity (seismic fragility). Then, the expansion of the event tree and fault tree models due to earthquake-induced initiating events is performed to identify the impact on the plant [4]. Finally, CDF and/or LERF quantification is made based on plant SSCs fragility (fragility curves) and probability of occurrence of seismic events (seismic hazard curves).

\section{METHODS}

The technical elements necessary for the development of a Seismic PSA are still analytically sophisticated and require extensive engineering judgment, as shown in Figure 1. Thus, in this article, focus is given on the existing guidance and current practices regarding the elements listed below:

- Seismic Hazard Analysis: consists of site characterization to determine the frequency of occurrence of seismic events for a given ground motion parameter (GMP). The main results of this analysis are Seismic Hazard Curves and Uniform Hazard Response Spectra (UHRS);

- Seismic Demand Analysis: based on the UHRS, Soil-Structure Interaction (SSI) is evaluated to verify site conditions and SSCs response to a given GMP level. The main product of this analysis is Floor Response Spectra (FRS);

- Seismic Fragility Analysis: based on the FRS, SSCs capabilities to support a given GMP level are assessed. SSCs Fragility curves are generated. In addition, weak links of plant systems may be identified for specific ground motion levels.

\subsection{Seismic Hazard Analysis}

In general, choosing the location or region in which a nuclear plant shall be installed is not a trivial task regarding safety evaluation for seismic hazards. It is known that the phenomenon characterization depends on local environmental conditions and the prediction of occurrence, location and magnitude of seismic events involves diverse uncertainties. 
Figure 1: Technical elements for Seismic PSA development.

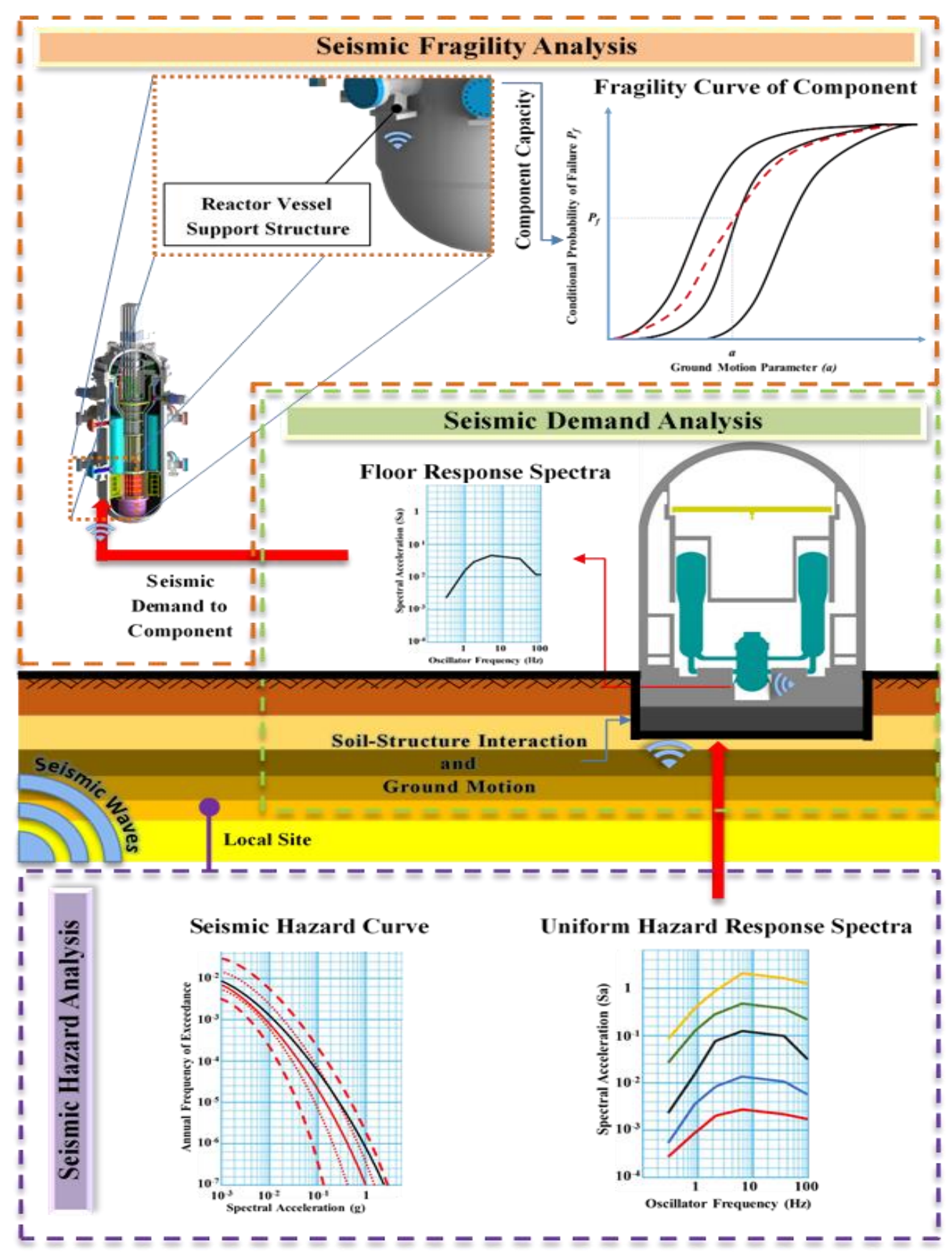

Source: Adapted from WEI-CHAU XIE et al (2019) [6]

A starting point for predicting calculations is the history of these events over time. In regions of high seismicity, i.e., where earthquakes occur with greater frequency and considerable magnitudes, associated with regional geology and existing faults, important data are provided for the formulation 
of prediction models of the phenomenon in a specific region. On the other hand, in low seismicity regions, the contribution of uncertainties, random and epistemic, in prediction models of seismic events is significant. The Brazilian territory is located on the South American Plate, which is a low seismicity region [5].

\subsubsection{Process Overview}

A seismic event is a large energy release natural phenomenon that propagates in mechanical waves and can follow different paths: the terrestrial mantle, which is the case of body waves, and the terrestrial crust, which is the case of surface waves. The latter ones can reach longer distances propagating through the terrestrial crust, where civil structures are founded [6]. These structures can experience any wave type at different times, but when the main event occurs associated with the major shock, the phenomenon lasts about 30 seconds, which is long enough to cause great destruction. In low to moderate seismicity regions - classified with degree VI - VII in the Modified Mercalli Intensity scale (MMI) - as the Brazilian territory, which is located in an intraplate area, waves reflections and refractions originated from great distances may be experienced [7].

Although there have been reports on seismic phenomena perceptions in Brazil since 1560 [8], the occurrence rate of activity with magnitudes that produce destructive effects is low. These low activity rates generally yield a small number of events of sufficient magnitude and/or ground motion amplitude that are significant regarding engineering or seismology studies. As a result, Ground Motion Prediction Equations (GMPEs) derived from these areas will have large uncertainties [9]. Moreover, the classification of GMPEs uncertainties into random and epistemic components is a complex task. Identification and characterization of seismic sources are also challenging activities [10].

A common practice for observing seismic phenomena behaviour in diffuse (low to moderate) seismicity zones is the comparison of this behaviour with results of prediction model parameters obtained from studies of similar intraplate regions. In this case, the work done for Thyspunt region, a rocky stretch on the Eastern Cape coast, province of South Africa [11], can be used in seismic analyses carried out for Brazil.

Probabilistic Seismic Hazard Analysis (PSHA) is a study that involves the characterization of seismic sources and ground motions. Thus, calculation of uncertainties involved in each 
characterization has an important role in the prediction models of a seismic event, mainly in regions of low seismicity. Uncertainties concerning Safe Shutdown Earthquake (SSE) determination can be considered in PSHA. However, assumptions adopted and methods applied to PSHA depend on site tectonic configuration and proper characterization of input parameters, making PSHA into a specific study for an area or a set of areas of the same seismic source [12].

In general, for the identification of all possible seismic events and resulting ground motions, along with their associated occurrence probabilities, PSHA can be performed following the steps below [13-14]:

- Treatment of input data for PSHA: a seismic phenomenon is analysed based on its time history, characterization of seismic sources and local geology. Two characterizations are performed: Seismic Source and Ground Motion. In the first part, qualitative and instrumental historical records of seismic events and failures in the region of interest are collected and compiled. Historical data magnitudes are homogenized in a moment magnitude (Mw). Then, an algorithm is used to exclude records obtained before and after earthquakes shock. The remaining main events are grouped in seismic source zones, in which magnitude-frequency relations, magnitude probability distribution and earthquake recurrence model are generated. In the second part, physical and mechanical characteristics of site similar regions are studied for the scaled backbone GMPEs. After backbone assembly, the selection of GMPEs compatible with the site of interest is made based on expert assessment. At the end of each characterization, earthquake size, location and ground motion uncertainties are combined, by using the total probability theorem, through the logic-tree models. This technique is used to identify and estimate epistemic uncertainties associated with the lack of knowledge about seismic processes, seismicity characteristics and ground motion in the specific region under study. For logic-tree models construction and generation of results, weights are defined from evaluations carried out by several specialists, having as starting point a specific database.

- Hazard calculations: based on the logic-trees developed in the previous step, maximum and minimum magnitudes for data integration are defined. PSHA results are generated from combination of logic-trees branches by using specific codes. Some examples are presented in sub-item 2.2. 
- Hazard results: the main results are Seismic Hazard Curves, Uniform Hazard Response Spectra and Disaggregation. Vertical Response Spectra and Response Spectra for alternative damping values may also be generated.

Activities performed in each step of PSHA process are shown in the flowchart of Figure 2.

Figure 2: Probabilistic Seismic Hazard Analysis (PSHA) process methodology.

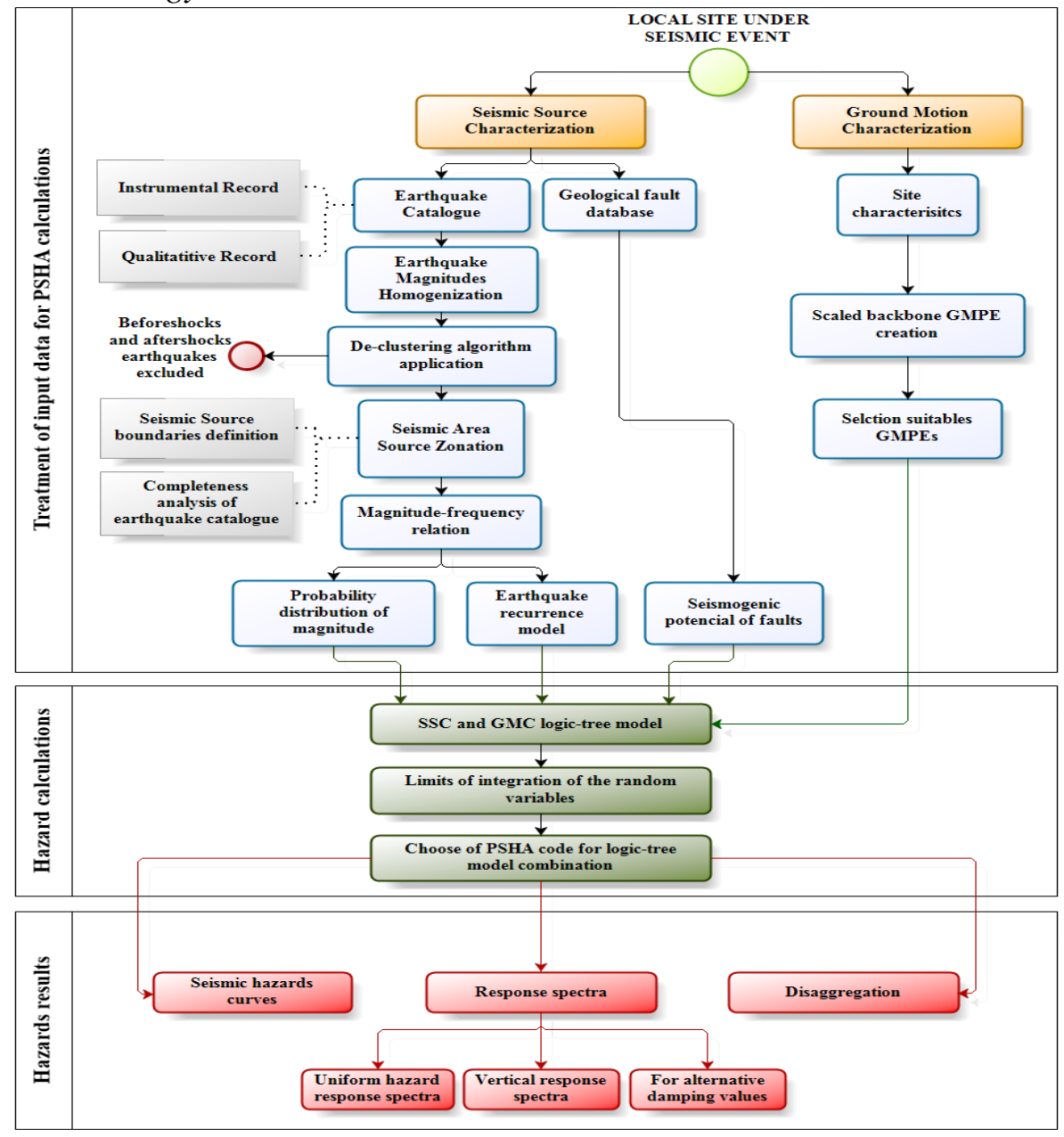

Source: Adapted from Almeida A.A.D. et al (2018) [7]

\subsubsection{PSHA computer codes}

Parameters considered in PSHA calculations follow probability distributions of random variables, and their integration, depending on study complexity, may require a significant number of operations 
and computational codes for numerical calculation. Examples of well-known and open source computational codes used in PSHA studies are OpenQuake (GEM Foundation) [15], R-CRISIS (Instituto de Ingeniería - Universidad Nacional Autónoma de México \& Evaluación de Riesgos Naturales - ER) [16] and OpenSHA (Field, E.H., Jordan, T.H., and Cornell, C.A.) [17].

\subsubsection{Main results}

\subsubsection{Seismic Hazard Curves}

Seismic hazard curve is the most important and most commonly used tool in seismic hazard analysis. It consists of a graph whose abscissa represents a Ground Motion Parameter (GMP) and the ordinate represents the Annual Frequency of Exceedance (AFE) of the observed value for this GMP. Several curves are plotted on a graph, in which the probability that a specific GMP level will be exceeded at the point of interest is determined. A hazard curve may be developed for each seismic source. The final hazard curve represents the sum of the rates at which a given GMP level is exceeded in each seismic source area. Some examples of seismic hazard curves for frequencies of 1, 10 and $100 \mathrm{~Hz}$ calculated for a specific area located in the Southeast region of Brazil are shown in Figure 3 [7].

Figure 3: Seismic hazard curves for 1,10 and $100 \mathrm{~Hz}$ frequencies in an area located in Brazil Southeast region.
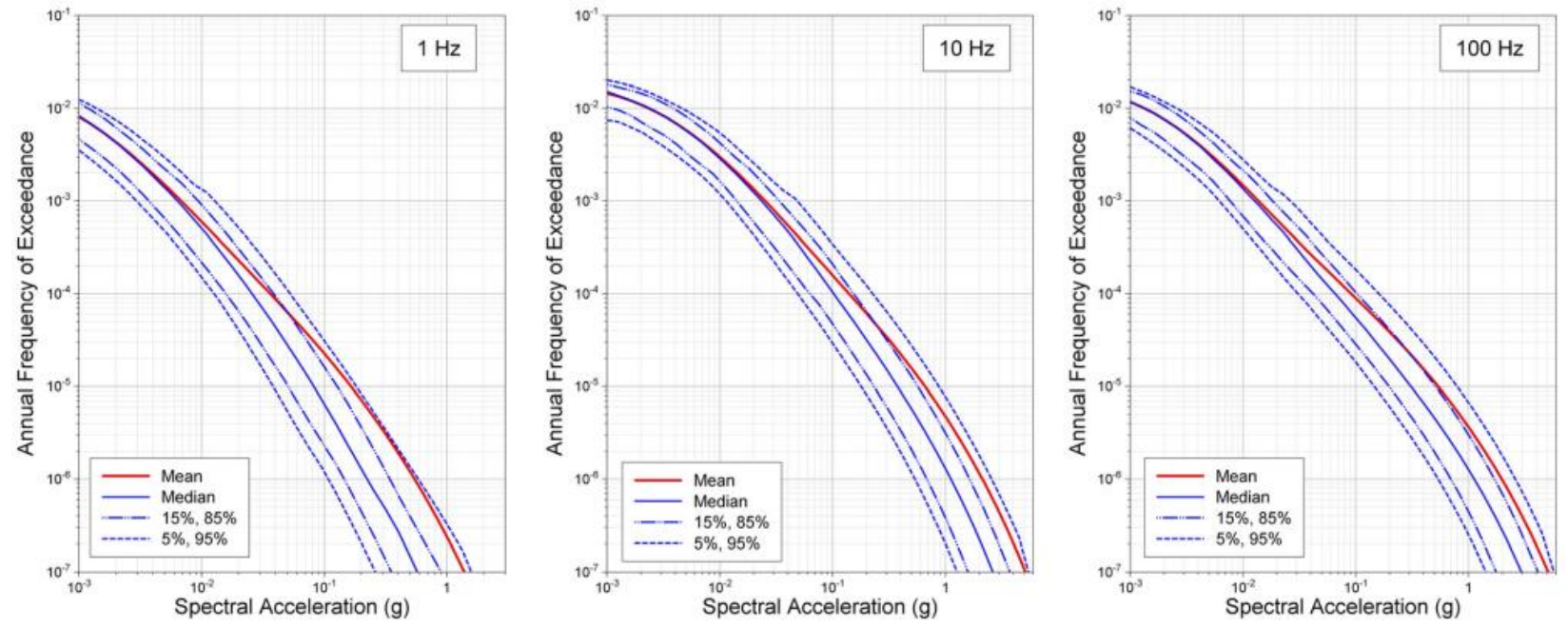

Source: Adapted from Almeida A.A.D. et al (2018) [7] 
The curves shown in Figure 3 are calculated as a function of Spectral Acceleration (Sa), which is a GMP, with their respective fractiles, mean and median. In the $100 \mathrm{~Hz}$ frequency plot, Spectral Acceleration equals Peak Ground Acceleration (PGA).

\subsubsection{Uniform Hazard Response Spectra - UHRS}

UHRS are response spectra obtained from mean hazard curves derived from a GMP (PGA or Sa, for example) at multiple responses frequencies, such that each acceleration value has the same AFE. UHRS is used to obtain Ground Motion Response Spectra (GMRS), which, in turn, is used as input for structural seismic loading calculation.

\subsubsection{Disaggregation}

Seismic hazard curves show combined effect of all magnitudes (M), distances (R) and standard deviations $(\varepsilon)$ in the calculation of GMP probability to exceed a certain value. Specific combinations or event scenarios in which M, R and $\varepsilon$ most contribute to seismic hazard are not easily identified. A common practice is to decompose the total probability of exceedance into different degrees of magnitude and distance. This allows for better identification of "seismic control events", i.e., subsets of seismic events responsible for ground motion severity level at the site of interest.

\subsection{Seismic Demand Analysis}

A seismic phenomenon consists of a large energy release in waveform and movement. Generally, GMPs used to characterize this movement are PGA or Sa. In projects that require seismic qualification for SSCs, determination of seismic phenomena intensities in a certain place of interest is fundamental for structural dimensioning, directly affecting construction costs. For nuclear plants, it is mandatory to demonstrate that ground accelerations will not result in damage to the structures and items supported therein [18], since acceleration amplification may occur - e.g., an acceleration of $0.1 \mathrm{~g}$ on a foundation can be amplified to $0.3 \mathrm{~g}$ at a higher level of the structure, and acceleration can reach $3 \mathrm{~g}$ or more on internal items fixed at this level. Civil structure interaction under seismic action may attenuate or amplify acceleration from the base motion. From the engineering point of view, damage shall be characterized in terms of intensity associated with a GMP, usually the PGA.

In order to verify ground effects under seismic event action in a specific place, their characteristics shall be analysed. Geological characterization generated in Seismic Hazard Analysis, specifically in 
local PSHA, provides information needed for this task. Acceleration amplifications in nuclear plant foundation may occur due to different materials (different module of elasticity) present in the ground. To reduce undesired effects, it is recommended to build the foundation on a competent material (rock) [18]. Thus, it can be considered that, approximately, ground motion (competent rock) will be the same as that of the foundation, simplifying structure calculations.

Structures dynamic finite element models of a nuclear plant are established and structures responses at specific locations are determined by dynamic structural analysis. If a plant is founded on soil (absence of competent rock), soil-structure interaction should be considered when performing dynamic structural analysis [6].

Site Response Analysis is performed to evaluate soil conditions effects on earthquake-induced motions at specific elevation levels, such as free surface or foundation level, due to shear waves propagation in the ground. In this way, results generated in this analysis are considered as input for Seismic Demand Analysis, which consists of structure response analysis based on the ground under study. Calculations involved in Site Response Analysis and Seismic Demand Analysis are shown in Table 1.

Table 1: Calculations performed in Site Response and Seismic Demand Analyses

\begin{tabular}{|c|c|}
\hline Analysis & Calculations \\
\hline Site Response & $\begin{array}{l}\text { - Development of input ground motions at reference hard rock } \\
\text { - Determination of geotechnical model for the site } \\
\text { - Calculation of amplification functions and strain-compatible soil } \\
\text { properties } \\
\text { - Determination of seismic hazard curves at foundation level } \\
\text { - Determination of GMRS and Foundation Input Response Spectra } \\
\text { (FIRS) }\end{array}$ \\
\hline Seismic Demand & $\begin{array}{l}\text { - Modelling of Structures } \\
\text { - Generation of Floor Response Spectra (FRS) based on Time-History, } \\
\text { Direct and Scaling methods } \\
\text { - Generation of FRS considering Soil-Structure Interaction (SSI) }\end{array}$ \\
\hline
\end{tabular}

Finally, seismic demand used for dimension plant SSCs determines structure capacity and FRS calculations. The latter term consists of a set of response spectra for each structure level, considering its inherent characteristics (mass-stiffness). FRS is the main input to qualify structure internal items, 
such as pipes, valves, electrical panels, etc. Thus, all seismic items will have appropriate seismic loading for their dimensioning and qualification.

\subsection{Seismic Fragility Analysis}

After having described the modeling of structural seismic demand in previous sections, it is necessary to identify plant fragility, that is, SSCs failure probabilities for a given level of ground motion parameter (PGA $[\mathrm{g}]$ or $\mathrm{Sa}[\mathrm{g}])$.

SSC seismic fragility can be given by:

$$
F(A)=P[S S C \text { failure } \mid G M P=a]
$$

With:

- $A=S S C$ ground acceleration capacity; and

- $\quad a=$ GMP level.

Due to lack of knowledge of actual SSCs seismic capacity, uncertainties associated with design, analysis, qualification test and construction can be expressed only in probabilistic terms and represented by a fragility curve [19].

Basic (standard) fragility model is based on a lognormal probability distribution:

$$
P_{F \mid a, Q}=\Phi\left(\frac{\ln \left(\frac{a}{A_{m}}\right)+\beta_{U} \Phi^{-1}(Q)}{\beta_{R}}\right)
$$

With the following parameters:

- $P_{F \mid a, Q}:$ conditional failure probability;

- $a$ : GMP level;

- $A_{m}$ : median ground acceleration capacity;

- $\beta_{R}$ : variability due to inherent randomness of response; 
- $\quad \beta_{U}$ : variability due to lack of knowledge of structural response and capacity uncertainties;

- $Q$ : desired confidence level associated with uncertainty variability; and

- $\Phi$ : standard Gaussian cumulative distribution function.

Mean fragility curve is calculated by using the equation below:

$$
P(a)=\Phi\left(\frac{\ln \left(\frac{a}{A_{m}}\right)}{\beta_{C}}\right)
$$

With a composite variability calculated by:

$$
\beta_{C}=\sqrt{\beta_{R}^{2}+\beta_{U}^{2}}
$$

One of the seismic fragility analysis objectives is to generate a family of curves expressed by fragility parameters. As shown in Figure 4, the conditional failure probability $P_{f}$ at acceleration $0.87 \mathrm{~g}$ and $95 \%$ confidence level may be obtained from Eq. 2 and it equals 0.79 . The [5\%; 95\%] confidence interval for the failure at $0.6 \mathrm{~g}$ is [0;0.79]. A mean fragility curve is obtained by using Eq. 3 but replacing $\beta_{R}$ with the composite variability $\beta_{C}$ using Eq. 4 . The median ground acceleration capacity $A_{m}$, and its variability estimates $\beta_{R}$ and $\beta_{U}$ are evaluated by taking into account safety margins inherent in capacity predictions, response analysis, and equipment qualification [19].

Finally, an important parameter in a seismic fragility analysis is the High Confidence of Low Probability of Failure (HCLPF), used as a screening criterion for high seismic capacity components based on a review of seismic qualification criteria and screening documents, and walkdown qualification. 
Figure 4: Fragility curves for SSC with $\mathrm{Am}=0.87 \mathrm{~g}, \beta_{\mathrm{R}}=0.25, \beta_{\mathrm{U}}$

$=0.35$ and composite fragility curve, with $\beta_{\mathrm{C}}=0.43$.

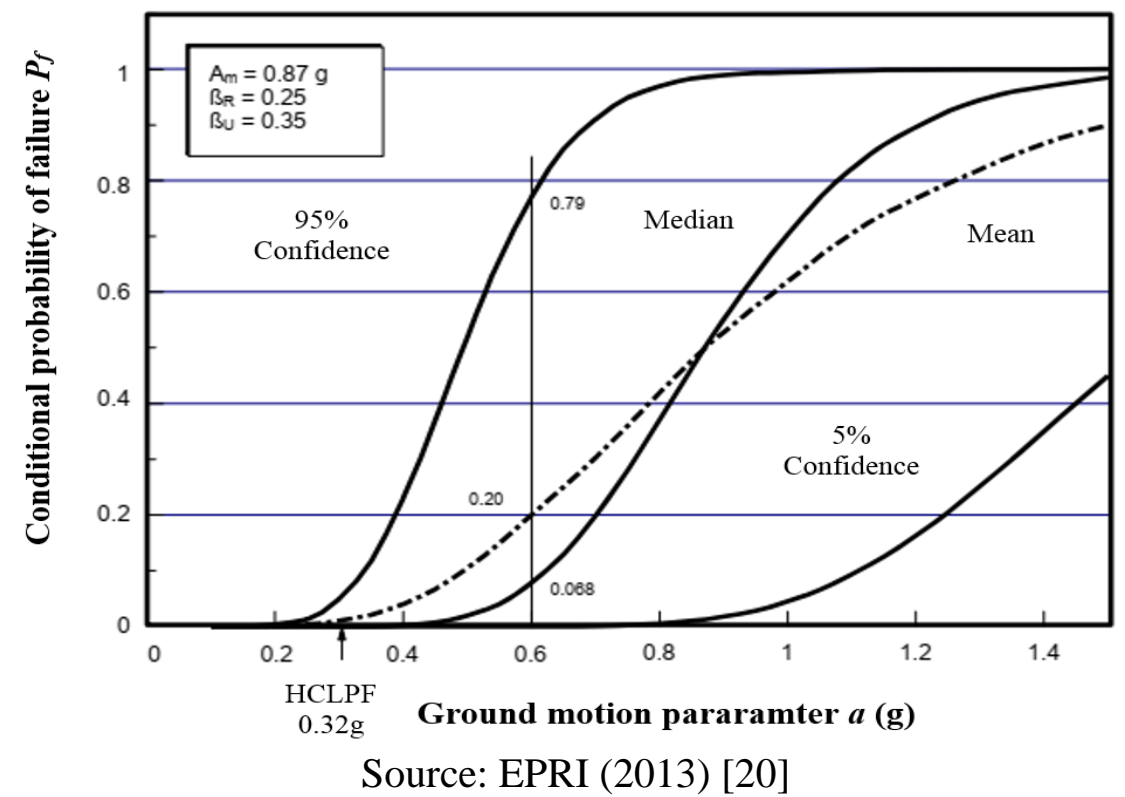

\section{IMPLEMENTATION OF SEISMIC ANALYSES RESULTS IN THE EXTENDED PLANT PSA MODEL}

In general, Seismic PSA is developed as an extension of Level 1 and/or Level 2 PSA for a nuclear installation, based on the supporting analyses described in sections 2, 3 and 4 . Thus, the extension of a Level 1 PSA involves quantification of seismic risk associated with a nuclear installation and results in a measure of the annual Core Damage Frequency (CDF) induced by seismic events.

To develop an extended Seismic Level 1 PSA, the steps listed below shall be followed [3, 6, 20]:

1. Selection of initiating events (IE) relevant for Seismic PSA (review of plant safety analyses);

2. Assembly of Seismic Equipment List (SEL) based on relevant IEs;

3. Assessment of SEL components by seismic capability engineers;

4. Extension of existing Level 1 PSA model, to include:

a. dedicated event trees for seismic event induced IEs;

b. fragility basic events in existing fault trees (SSCs relevant to mitigate seismic event induced IEs shall be modelled and fragility analysis of selected SEL components should include walkdown observations); 
c. fragility parameters imported from Seismic Fragility Analysis;

d. seismic events impact on Human Reliability Analysis performed for Level 1 PSA model;

5. Quantification of seismic induced CDF.

Risk quantification is performed by appropriate integration of seismic hazard, SSCs fragilities and Level 1 PSA model of the plant. Once hazard curves and fragility curves for a failure event are obtained, two sets of curves are combined two at a time (i.e. one hazard curve and one fragility curve) to obtain the probability distribution of unconditional $\mathrm{CDF}$, named $\mathrm{P}_{\mathrm{F}}$, as presented in Equation 5.

$$
P_{F}=\int_{0}^{\infty} H_{a} \frac{d P_{f / a}}{d a} d a
$$

With:

- $\quad a$ : GMP level;

- $H_{a}$ : mean annual frequency of the hazard curve with respect to GMP level $a$; and

- $D P_{f / a}$ : derivative of conditional failure probability (fragility curve).

\section{CONCLUSION}

The basic parts of a Seismic PSA for nuclear installations consist of seismic hazard identification, systems (or SSCs) analysis, plant seismic fragility evaluation, and risk quantification. Various guidelines are publically available, providing practical methods and covering a broad spectrum of PSA tasks. Some basic elements of Seismic PSA are still analytically sophisticated and require extensive engineering judgement. To elaborate appropriate guidelines to extend PSA for seismic hazards, it is crucial to have support of a multi-disciplinary team of specialists (seismologists, structural integrity engineers, geologists, etc.).

In this article, the supporting analyses for Seismic PSA were described in a simplified way. In Seismic Hazard Analysis, emphasis was placed on the methodology for epistemic uncertainties 
evaluation, which may represent a great contribution to nuclear plant structural design. It is important to note that PSHA shall be carried out specifically for the region of interest. Epistemic uncertainties associated with lack of sufficient historical records compromise adequate seismic events characterization and prediction in low seismicity regions, especially events with higher degrees of intensity. This applies to the Brazilian territory, where seismic events with intensities greater than VII on the MMI scale have not been experienced yet [7 - 8]. Seismic Demand Analysis, which covers structure response under a load originated from ground motion, depends on local geological characteristics. It is recommended to reduce SSI and install foundation on a competent rock. After that, FRS of plant structure is considered the main input data for design and qualification of SSCs that will be fixed at each level. This design is directly linked to SSCs Seismic Fragility Analysis, by means of which SSCs failure probabilities are calculated for a given ground acceleration. Fragility parameters are calculated and incorporated into event tree and fault tree models developed in plant Level 1 PSA. Based on these results, SSCs weak links identification, especially those which perform safety functions, may facilitate decision-making processes regarding plant safety

It is important to mention that the methodology presented in this article will be used to evaluate seismic induced CDF of an experimental nuclear installation containing a PWR reactor designed for naval propulsion to be installed in the southeast region of Brazil. In this case, it is essential to highlight that a plant specific Level 1 PSA for internal events and operation at-power has been performed. This study will be considered as the base PSA for Seismic PSA development. Finally, for future research, it would be advisable to develop computational codes that could integrate all seismic support analyses required for the extension of Level 1 PSA to Seismic PSA.

$\begin{array}{ll}\text { ACRONYMS } & \\ \text { AFE } & \text { Annual Frequency of Exceedance } \\ \text { CDF } & \text { Core Damage Frequency } \\ \text { DSA } & \text { Deterministic Safety Analysis } \\ \text { FRS } & \text { Floor Response Spectra } \\ \text { FIRS } & \text { Foundation Input Response Spectra } \\ \text { GMP } & \text { Ground Motion Parameter } \\ \text { GMPE } & \text { Ground Motion Prediction Equations } \\ \text { GMRS } & \text { Ground Motion Response Spectra }\end{array}$


IE

HCLPF

LERF

MMI

PGA

PSA

PSHA

PWR

SEL

SSE

Seismic PSA

SSCs

SSI

UHRS
Initiating Events

High Confidence of Low Probability of Failure

Large Early Release Frequency

Modified Mercalli Intensity

Peak Ground Acceleration

Probabilistic Safety Assessment

Probabilistic Seismic Hazard Analysis

Pressurized Water Reactor

Seismic Equipment List

Safe Shutdown Earthquake

Seismic Probabilistic Safety Assessment

Structures, Systems and Components

Soil-Structure Interaction

Uniform Hazard Response Spectra 


\section{REFERENCES}

[1] IAEA - International Agency Energy Atomic - IAEA. Fundamental Safety Principles. IAEA Safety Fundamentals No SF-1. IAEA, 2006.

[2] ASME - The American Society of Mechanical Engineers. Standard for Level 1/Large Early Release Frequency Probabilistic Risk Assessment for Nuclear Power Plant Applications. ASME-ANS RA-Sb-2013. ASME, 2013.

[3] IRNS - Institute For Radiological Protection And Nuclear Safety. Guidance document on practices to model and implement SEISMIC hazards in extended PSA. IRSN ASAMPSA_E WP22/ D50.15/ 2017-33/v. 2. IRNS, 2017.

[4] RAUSAND, M.; HOYLAND, A. System Reliability Theory Models and Statistical Methods. 2004. Available at: https://notendur.hi.is/hthb1/\%C3\%81rei\%C3\%B0anleiki\%20kerfa/System \%20Reliability\%20Theory\%20Models\%20and\%20Statistical\%20Methods.pdf $>$. Last accessed: Jan. 2019.

[5] USGS - United States Geological Survey. The layer of the Earth we live on is broken into a dozen or so rigid slabs (called tectonic plates by geologists) that are moving relative to one another. 2011. Available at: <https://pubs.usgs.gov/gip/dynamic/slabs.html>. Last accessed: Jan. 2019.

[6] WEI-CHAU XIE et al. Seismic risk analysis of nuclear power plants. $1^{\text {st }}$. New York: Cambridge University Press, 2019.

[7] ALMEIDA, A. A. D.; Assumpção, M.; BOMMER, J. J.; DROUET, S.; RICCOMINI, C.; PRATES, C. L. M.; Probabilistic seismic hazard analysis for a nuclear power plant site in southeast Brazil. Journal of Seismology, v. 23, pp 1-23, 2018.

[8] BERROCAL, J. et al. Sismicidade do Brasil, $1^{\text {st }}$ ed. São Paulo: Editora Esperança - IAG/USP, 1984.

[9] DOUGLAS, J. Ground motion prediction equations 1964-2018. 2019. Available at: <http://www.gmpe.org.uk/gmpereport2014.pdf>. Last accessed: Jun. 2019.

[10]AKE, J. Uncertainties in Probabilistic Seismic Hazard Analyses for Regions of Low-toModerate Seismic Potential: The Need for a Structured Approach. 2012. Available at: <https://www.nrc.gov/docs/ML0808/ML080870337.pdf>. Last accessed: Jun. 2018. 
[11]BOMMER, J. J. et al. A SSHAC Level 3 Probabilistic Seismic Hazard Analysis for a New-Build Nuclear Site in South Africa”, Earthquake Spectra, v. 31, No. 2, pages 661-698, 2015.

[12]U.S. NRC - United States Nuclear Regulatory Commission. Performance-based approach to define the site-specific earthquake ground motion. U.S.NRC Regulatory Guide 1.208. U.S. NRC, 2007.

[13]U.S. NRC - United States Nuclear Regulatory Commission. Recommendations for Probabilistic Seismic Hazard Analyses: Guidance on Uncertainty and Use of Experts. U.S. NRC NUREG-CR-6372. U.S. NRC, 1997.

[14]BAKER, J. W. Introduction to Probabilistic Seismic Hazard Analysis. 2013. Available at: <https://web.stanford.edu/ bakerjw/Publications/Baker_(2013)_Intro_to_PSHA_v2.pdf>. Last accessed: Jun. 2018.

[15]GEM - Global Earthquake Model Foundation. Open Quake (OQ). 2019. Available at: <https://docs.openquake.org/manuals/OpenQuake\%20Manual\%20\%28latest\%29.pdf>. Last accessed: Jan. 2019.

[16]ORDAZ M. AND SALGADO-GÁLVEZ M.A. R-CRISIS Validation and Verification Document. 2019. Available at: <http://www.r-crisis.com/Content/files/RCRISIS\%20V_AND_V\%20Document_V1\%20Full\%20document.pdf >. Last accessed: Jan. 2019.

[17]FIELD, E.H., T.H. JORDAN, AND C.A. CORNELL OpenSHA: A Developing CommunityModelling Environment for Seismic Hazard Analysis, Seismological Research Letters, 74, no. 4, p. 406-419, 2003.

[18]U.S. NRC - United States Nuclear Regulatory Commission. 10 Code of Federal Regulation Appendix S to Part 50 - Earthquake Engineering Criteria for Nuclear Power Plants. U.S. NRC, 2007.

[19]EPRI - Electric Power Research Institute. Seismic Fragility Application Guide. EPRI Technical Report 1002988, Palo Alto: EPRI, 2002.

[20]EPRI - Electric Power Research Institute. Seismic Probabilistic Risk Assessment Implementation Guide. EPRI Technical Report 3002000709, Palo Alto: EPRI, 2013. 